International Journal of Wireless \& Mobile Networks (IJWMN) Vol. 3, No. 6, December 2011

\title{
A STUdy OF Voice TRAFFiC BLOCKING IN A Model Cellular Network
}

\author{
Oliver Mitch Maguitte로 Mohammad Sameer Sunhaloo ${ }^{1}$, Ben Oodit and Vinaye \\ Armoogum $^{1}$ \\ ${ }^{1}$ School of Innovative Technologies and Engineering, University of Technology, \\ Mauritius \\ moliviermegmail.com, sameer.s@utm.intnet.mu, ben.oodit@gmail.com and \\ varmoogumeutm. intnet.mu
}

\begin{abstract}
In this paper, we present results obtained from a statistical analysis of a model cellular network which is similar to the one used in Mauritius. We have tested system samples with different cell cell configurations with two to four transceiver units, which serve a delimited region of several square kilometres. The Erlang B, Erlang $C$ and Poisson models have been considered in this study. The experimental work has showed that the Erlang $C$ Model provided the closest match for the studied environment.
\end{abstract}

\section{KEYWORDS}

Cellular Network, Voice Traffic, Erlang B, Erlang C

\section{INTRODUCTION}

GSM (Groupe Spécial Mobile) technology is used worldwide and is the basis of public mobile telecommunication $[6,12,13]$. Mobile networks have adopted the cellular concept for reasons related to capacity, flexibility, scalability and cost effectiveness. Currently there are 3 GSM operators in Mauritius and mobile penetration is reported to be $92 \%$ by the ICTA (Information and Communication Technologies Authority of Mauritius), the Mauritian regulator [17, 18].

Mobile networks are traffic sensitive due to the rapid increase of subscribers throughout the world. It is thus crucial to save on operating cost and to consume bandwidth effectively with respect to traffic load as spectrum is limited. There exist many traffic models and not all of them may be appropriate for a specific cellular network system. Since, different traffic models behave differently due to differences in underlying assumptions, one model may prove to be more useful and provide more realistic feedback of the performance of a given network than others. These traffic models help in traffic engineering by highlighting bottlenecks which can be proactively handled by the mobile operator through the optimization of cell capacity.

Based on the ability of traffic models to simulate real-life conditions, appropriate models have been developed so as to approximate blocking probabilities in order to help network engineers in dimensioning $[3,9,10,11]$. Some common factors which affect blocking probabilities are call arrival patterns, number of servers (or channels), channel holding time and traffic intensity $[15,16]$. Most operators throughout the world favour the use of the Erlang B model for blocking probability but that model was initially developed for fixed telephone networks and mainly trunks. The Erlang B model has been ported to mobile telephone network for dimensioning the air interface.

Although traffic distribution has been an active research, only a few researchers have been questioning the reliability of different traffic models, including the famous Erlang B for mobile networks at cell level. Tunnicliffe et al. [16] and Smith et al. [15] cleared doubts about the 
accuracy of using a single model, like Erlang B model, to evaluate call blocking. Investigations of several parameters like arrival rate, mean holding time, with varying sample size and network resources have led to the conclusion that Erlang B is not appropriate for cells with less than 12 traffic channels as blocking tends to be over estimated. However, Erlang B does provide a good model for cells with number of channels greater than 12 and with blocking rate above $1 \%$.

In this paper, we investigate the appropriateness of various models, including the Erlang B model, for the estimation of blocking at the air interface of a model mobile network. The focus is on the voice call class of service.

\section{RELATED WORK}

The distribution of channels holding and inter-arrival times were analyzed using real-life data by Jedrzycki and Leung [8]. They observed that calls which had been handoff from previous cells had low holding times. Weak signals were another cause of calls handoff. The holding time followed a lognormal distribution and not a negative exponential distribution. However, call inter-arrival times followed approximately a negative exponential distribution.

Rappaport and Lon-Rong Hu [14] studied the concept of layered cells, in which different cells help with the traffic load at various levels. Different parameters like blocking, carried traffic, forced terminations and handoff failures were observed. The aim was to find improvements on coverage which could be achieved with more capacity. It was noted that frequency reuse was more efficient with smaller cells. They also considered handoff interruption. Through simulations with different cell layers, it was noted that both the higher and the lower layers could be helpful to each other in reducing congestion under low and moderate offered traffics.

Land to mobile communications and mobile to mobile calls based on Erlang and Engset were studied by Baky and Ackroyd in 1981 [1]. Calls in the same cell were considered. We note that in reality calls are between cells of different base stations. They derived formulae for measuring congestion in a single cell. It was noted that average traffics gave a better picture of blocking probabilities as in real-life different types of calls are mixed. In 1982, Baky and Ackroyd studied a multi cell mobile radio telephone system in view of deriving formulae related to congestion [2]. They considered calls towards other networks, to mobile phones in other locations and calls to mobiles served by the same cell. The main concern of the study was to minimize congestion within a radio mobile telephone system. The study was made on 30 cells and it was found that dynamic channel allocation resulted in more congestion compared to fixed allocation.

In [7], Jabbari studied a new generation of networks by considering various parameters including voice service. He investigated about the strength of signal and propagation variation for a micro cell located in a region. He also presented an overview of different factors concerning mobility and layers. A model based on fluid flow assumptions was used to have a better system capacity based on parameters like traffic carried and different blocking probabilities.

Guerin performed simulations with some assumptions, like mobility of mobile phones towards a fixed direction, to investigate about channel occupancy, the distribution of holding time and to derive a model for channel occupancy [5]. It has been noted that channel occupancy is exponential even when mobile phones move across the cells. This study did help to make proper dimensioning and better estimation of handoff traffic.

In this paper, we concentrate on the voice traffic and the performance of network for standard cells using less than 5 transceiver units. 


\section{MODEL CELLULAR NETWORK}

We consider a model cellular network, where generated traffic measurement is close to real life conditions. The measurements in real life are typically obtained from the Base Station Subsystem Performance Management System, part of the OSS (Operation and Support System), following the parsing of scanner files containing cell level counters. Voice traffic in different clutter categories as described in Table 1 was analyzed.

Table1. Number if cells in different clutters

\begin{tabular}{|l|c|c|}
\hline & Rural & Urban \\
\hline Commercial & 4 & 3 \\
\hline Residential & 11 & 1 \\
\hline
\end{tabular}

The model network consisted of standard cells with the number of transceiver units ranging from two to four. For any standard cell to work it is mandatory to have one broadcast and at least one signalling channel configured and the others configured as traffic channels. For instance, 2 Transmitter/Receiver (Transceiver) TRX consists of 14 Traffic Channels (TCH) whilst 4 TRX consists of $28 \mathrm{TCH}$. Each channel is mapped onto a time slot. The cells are located in different regions and thus are able to sample varying traffic patterns.

\subsection{Physical Layout of Scenario}

The layout configuration of our model network is listed in Tables 2 and 3, where BCCH means Broadcasting Control Channel (Control Info), PDCH represents Packet Data Channel (Data Traffic) and SDCCH stands for Slow Dedicated Control Channel (Signalling).

Table2. Cells configuration for control channels and respective clutter serving with one BCCH.

\begin{tabular}{|c|c|c|c|c|}
\hline Location & TRX & SDCCH & Physical TCH & Logical TCH \\
\hline C RR 0 & 3 & 1 & 22 & 33 \\
\hline C RR 1 & 3 & 1 & 22 & 33 \\
\hline C RR 2 & 3 & 1 & 22 & 33 \\
\hline L RR 0 & 2 & 1 & 14 & 14 \\
\hline L RR 1 & 2 & 1 & 14 & 24 \\
\hline L RR 2 & 2 & 1 & 14 & 24 \\
\hline Z RR 0 & 2 & 1 & 14 & 14 \\
\hline Z RR 1 & 2 & 1 & 14 & 14 \\
\hline Z RR 2 & 2 & 1 & 14 & 14 \\
\hline W RC 0 & 2 & 1 & 14 & 14 \\
\hline W RC 1 & 2 & 1 & 14 & 24 \\
\hline W RC 2 & 4 & 3 & 28 & 53 \\
\hline D RC 0 & 2 & 1 & 14 & 14 \\
\hline D RR 1 & 2 & 1 & 14 & 14 \\
\hline D RR 2 & 2 & 1 & 14 & 14 \\
\hline A UR 0 & 2 & 1 & 14 & 14 \\
\hline B UC 0 & 2 & 1 & 14 & 14 \\
\hline B UC 1 & 2 & 1 & 14 & 14 \\
\hline B UC 2 & 2 & 1 & 14 & 14 \\
\hline
\end{tabular}


International Journal of Wireless \& Mobile Networks (IJWMN) Vol. 3, No. 6, December 2011

Table3. Logical traffic channel configuration per cell considering half rate activation with respective clutter.

\begin{tabular}{|c|c|l|c|}
\hline Location & Clutter & Area & Logical TCH \\
\hline C RR 0 & Rural & Residential & 22 \\
\hline C RR 1 & Rural & Residential & 22 \\
\hline C RR 2 & Rural & Residential & 22 \\
\hline L RR 0 & Rural & Residential & 14 \\
\hline L RR 1 & Rural & Residential & 14 \\
\hline L RR 2 & Rural & Residential & 14 \\
\hline Z RR 0 & Rural & Residential & 14 \\
\hline Z RR 1 & Rural & Residential & 14 \\
\hline Z RR 2 & Rural & Residential & 14 \\
\hline W RC 0 & Rural & Commercial & 14 \\
\hline W RC 1 & Rural & Commercial & 14 \\
\hline W RC 2 & Rural & Commercial & 28 \\
\hline D RC 0 & Rural & Commercial & 14 \\
\hline D RR 1 & Rural & Residential & 14 \\
\hline D RR 2 & Rural & Residential & 14 \\
\hline A UR 0 & Urban & Residential & 14 \\
\hline B UC 0 & Urban & Commercial & 14 \\
\hline B UC 1 & Urban & Commercial & 14 \\
\hline B UC 2 & Urban & Commercial & 14 \\
\hline
\end{tabular}

\subsection{Physical Topology of Selected Network}

Our model network simulates a mountainous topology. Target threshold for this segment is 5\% Grade of Service which is acceptable taking in consideration the landscape and access facility to the sites. In Figures 1 and 2, the topology and coverage zone of the cells used for the experiments are shown.

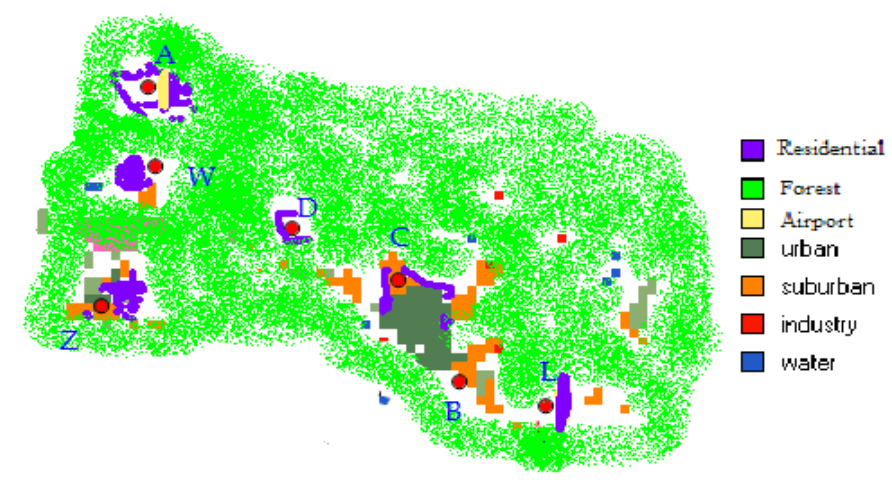

Figure 1. Topology of model network 


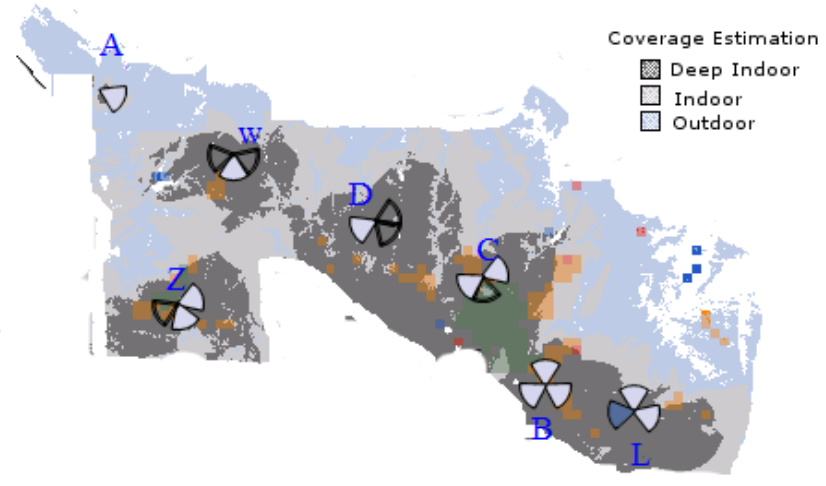

Figure 2. Coverage zone of model network

We note that the residential regions $\mathrm{C}, \mathrm{D}, \mathrm{L}, \mathrm{W}$ and $\mathrm{Z}$ include rocky valleys with steep slopes and forest. There is also a nature park surrounded by forests. The residential zones A and B are more developed, with location $\mathrm{B}$ being mainly a commercial zone with many shops and major banks in the surroundings. An airport is situated near Location A.

\subsection{Measurement}

Traffic measurement files for the model network had to be captured over several days on an hourly period from the BSS (Base station subsystem) and transferred to the OSS (Operation and Support System) performance monitoring tool. Individual cell KPI (Key Performance Indicator) were obtained and processed from the individual hourly measurement traffic files. To ensure the model network performance is not altered, only routine maintenance was performed with no modification to antenna settings and cell configuration, which led to constant and standard sampling with the only variation of subscribers which perform calls in a random and uncontrolled manner.

\section{TRAFFIC MODELLING}

Among the various types of traffic models which exist, only some are commonly employed in real life environment by operators based on arrival rate within the network. The models help operators to know about the blockings faced by users within their networks $[4,15,16]$. The different types of traffic model are discussed below.

Traffic Intensity is related to average call duration multiply by the average number of call requests and is measured in a dimensionless unit which is the Erlang. When one radio resource channel is utilized for one hour, it is said that 1 Erlang of traffic has flowed through. Clearly,

$$
A_{C}=\lambda h,
$$

where

- $A_{C}$ is the traffic intensity in Erlang generated by each user,

- $\quad h$ is the average duration of a call measured in hour and

- $\lambda$ is the average number of call requests per hour. 


\subsection{Erlang B}

Erlang B is a distribution originally used by Public Switched Telephone Network to dimension trunks. However, it is also applicable to mobile telephone network dimensioning of air interface. This model is employed when callers do not reattempt when they face a block call as the system reroute the call so as it does not return to the original cell where call is initiated. In the Erlang B model, it is assumed that the number of sources is infinite, calls arrive randomly and are served in order of arrival, blocked calls are lost and holding times are exponentially distributed. The Erlang B loss probability $B_{B}$ is given by

$$
B_{B}=\left(\frac{A^{N}}{N !}\right) / \sum_{i=0}^{N} \frac{A^{i}}{i !},
$$

where $N$ and $A$ denote the number of trunks available in resource group and traffic offered to group in Erlangs, respectively.

\subsection{Erlang C}

The Erlang C model is popular in networks where queuing is applied. Calls are not rerouted as in the case of the Erlang B model, but are put in a waiting queue until resources are free for call to be processed or queue time expires. Thus, in the Erlang $\mathrm{C}$ model, blocked calls are delayed. The relationship between $B_{B}$ and the Erlang $C$ probability of blocking $B_{C}$ is given by

$$
B_{C}=\frac{N E_{B}}{N-A\left(1-B_{B}\right)} .
$$

It should be noted that when resources start to be unavailable, for the Erlang $\mathrm{C}$ model the blocking rate is higher as it take in consideration the number of instances in the queue and the resources utilized.

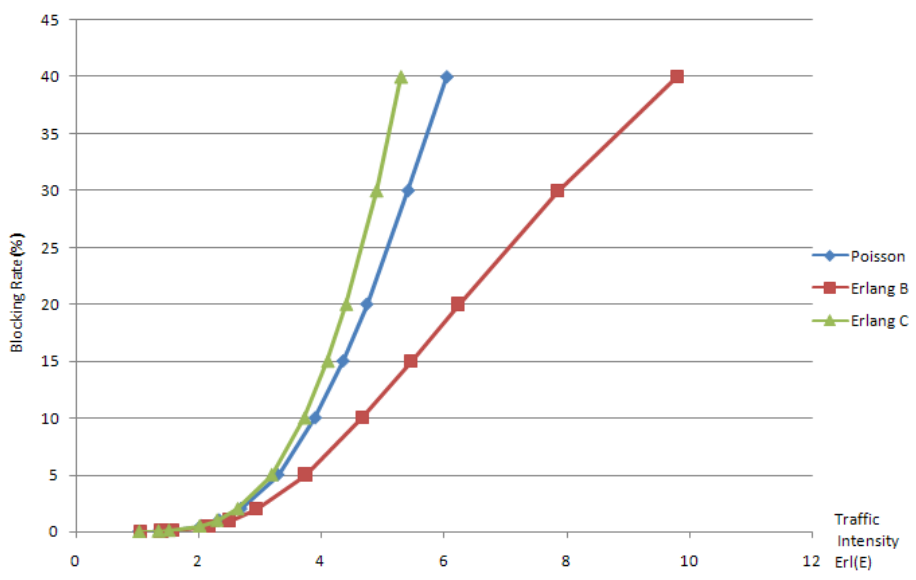

Figure 3. Traffic model comparison with limited servers (7 TCH). 
International Journal of Wireless \& Mobile Networks (IJWMN) Vol. 3, No. 6, December 2011

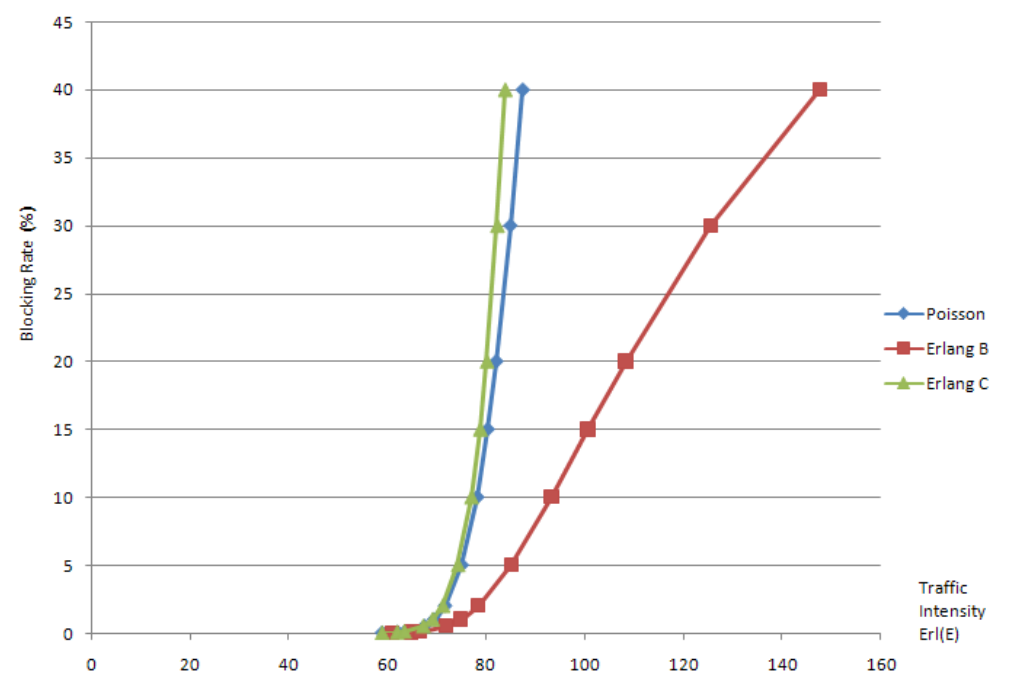

Figure 4. Traffic model comparison with huge number of servers $(90 \mathrm{TCH})$.

Figures 3 and 4 show that Erlang $\mathrm{C}$ for any cell with more than 14 channels installed behaves nearly like the Poisson traffic model. Erlang $\mathrm{C}$ behaves as Erlang B as long as the channel in busy state does not reach number of channel installed. When there is no blocking, Erlang $\mathrm{C}$ behaves similarly to Erlang B as seen in Figure 3 and 4.

\section{NETWORK BEHAVIOUR AND ANALYSIS OF DATA}

In this section, measured blockings are compared with theoretical values based on the traffic models, Erlang B and Erlang C depending on system being investigated. The sample size of the measured values has been made over a period for the same cell with no alteration to both the physical equipments and logical parameters, ensuring that the test bed being in the same condition for the sampled period. Figure 5 illustrates the arrival rate over a 24 hour period. In practice, the study of the arrival instances at a finer granularity is hard to obtain as it involves a huge load on the Operation Support Subsystem and network equipment storing the scanner files. Thus, we considered values for a day only.

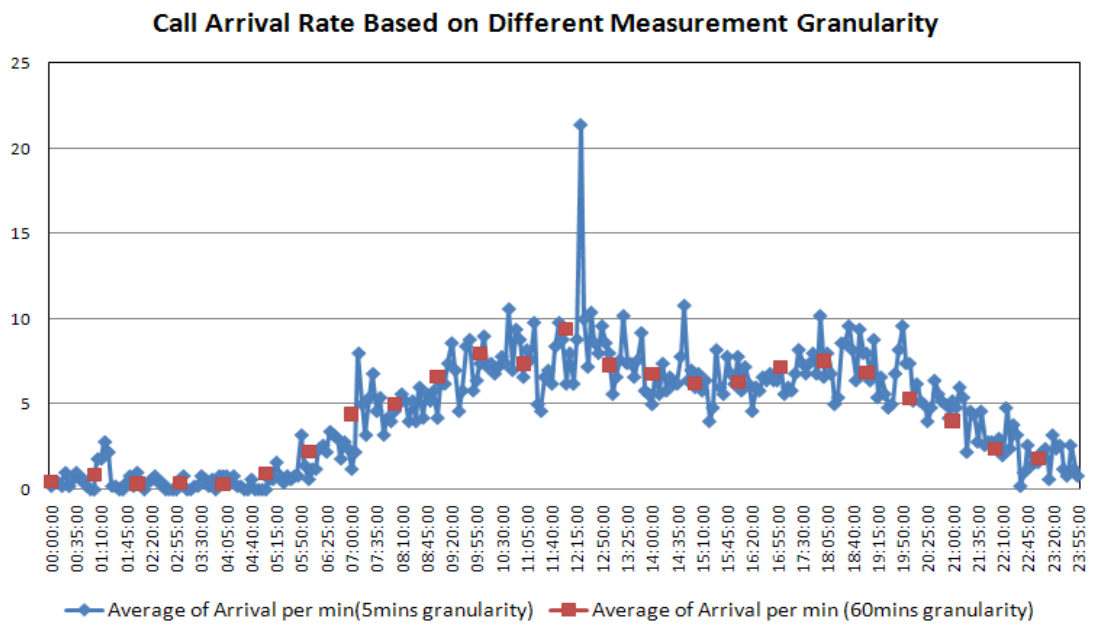

Figure 5. Call arrivals per minute and per hour. 
In Figures 6 and 7, the plots of blocking probability against traffic intensity for cells with 14 and 33 voice channels, respectively, are given. Due to the dynamic nature of the network and features implemented, it can be noticed that more traffic is carried with less blocking for some instances, but most of the time adhere to the assumptions made.

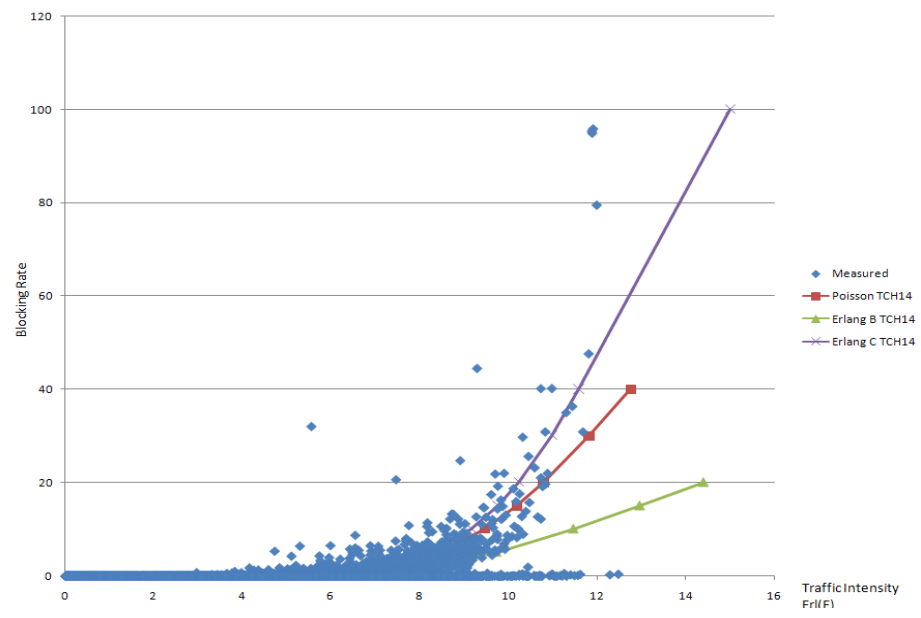

Figure 6. Graph of blocking rate against traffic intensity of collected data, Poisson, Erlang B, Erlang C for $14 \mathrm{TCH}$ cells.

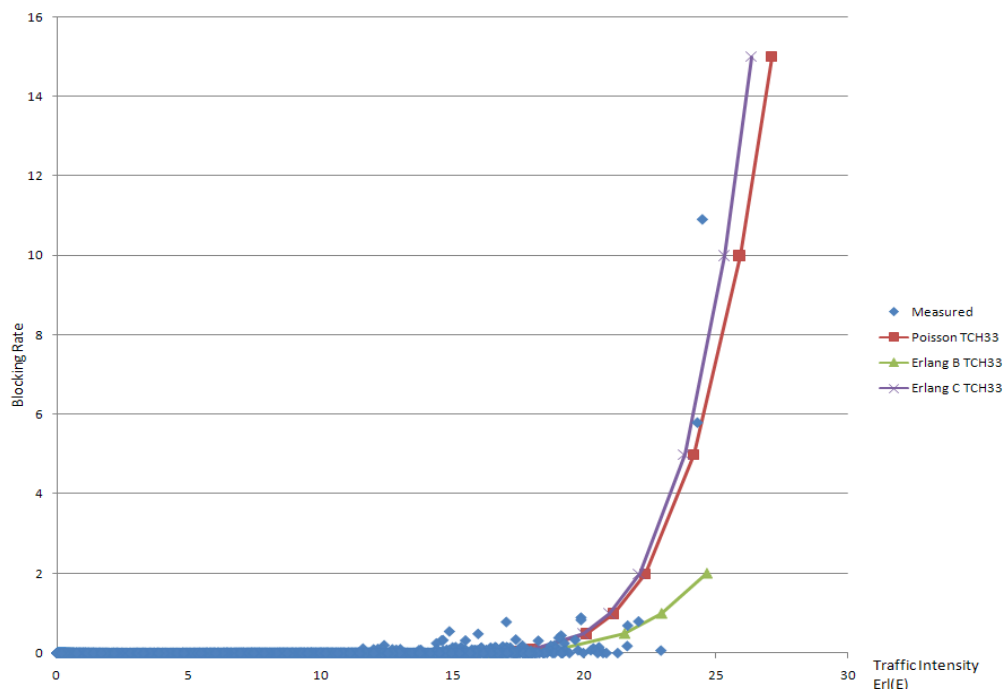

Figure 7. Graph of blocking rate against traffic intensity of collected data, Poisson, Erlang B, Erlang C for $33 \mathrm{TCH}$ cells.

\subsection{Data Analysis}

In this section, the data captured from the Operation Support Subsystem is analysed in details and selected graphs are plotted to illustrate the trend and comparison of measured against theoretical values. The network segment has different cells with 2, 3 and 4 TRX.

First we consider $14 \mathrm{TCH}$ cells. As shown in Figure 6, the Erlang $\mathrm{C}$ theoretical value lies midway in most cases. There are some values which do not follow the Erlang $\mathrm{C}$ model but this can be explained by the use of GSM features to manage load in cells. The Erlang B Model is not proper as measured blocking is higher than the hypothetical values. Each point referred as 
measured represent a measured value captured during the sampling duration and is usually archived by the Key Performance Indicator (KPI) system.

Figure 8 shows a $95 \%$ confidence interval calculated based on the measured information. It can be seen clearly that the Erlang $\mathrm{C}$ model for this class of cells with $14 \mathrm{TCH}$ fit within the confidence limits.

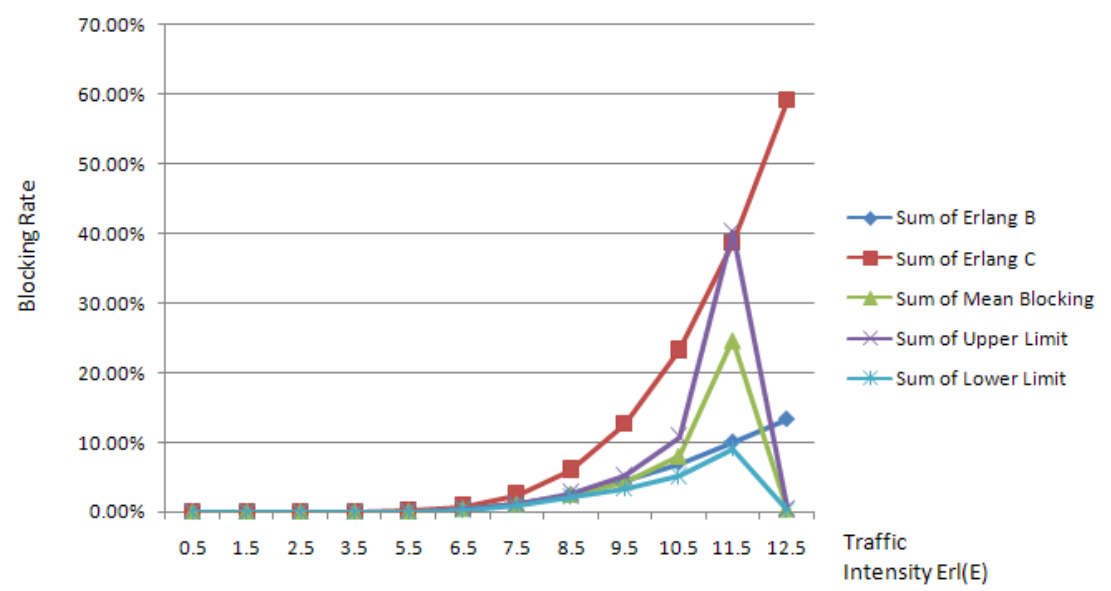

Figure 8. Confidence interval for all cells with $14 \mathrm{TCH}$.

Next, we consider $53 \mathrm{TCH}$ cells. The graph of blocking probability against traffic intensity is given in Figure 9.

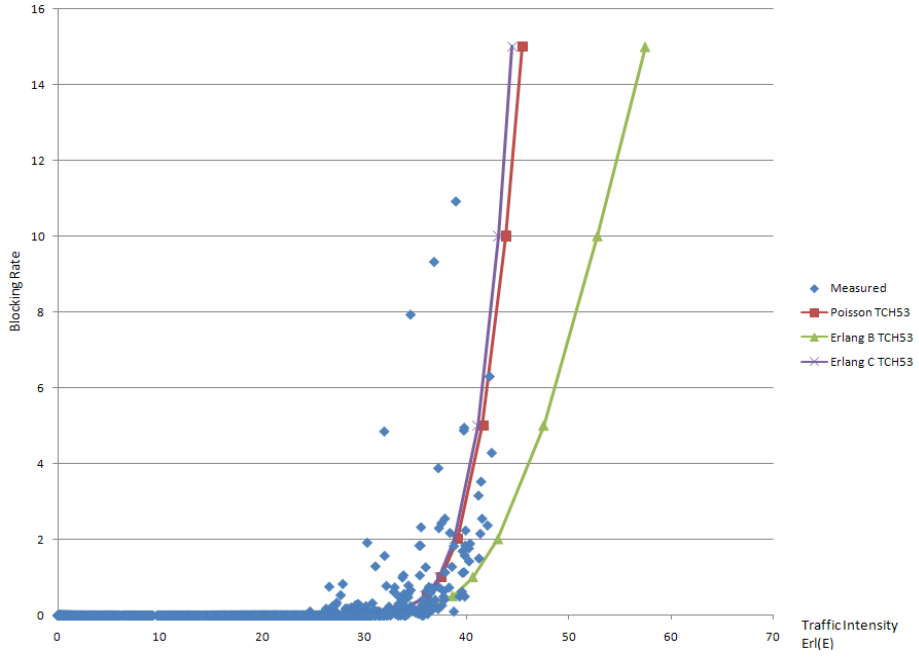

Figure 9. Graph of blocking rate against traffic intensity of collected data, Poisson, Erlang B, Erlang C for $53 \mathrm{TCH}$ cells.

Figure 10 shows the confidence interval calculated based on the measured information. It can be seen clearly that the Erlang $\mathrm{C}$ model for cells with $53 \mathrm{TCH}$ also fit within the confidence limits. 
International Journal of Wireless \& Mobile Networks (IJWMN) Vol. 3, No. 6, December 2011

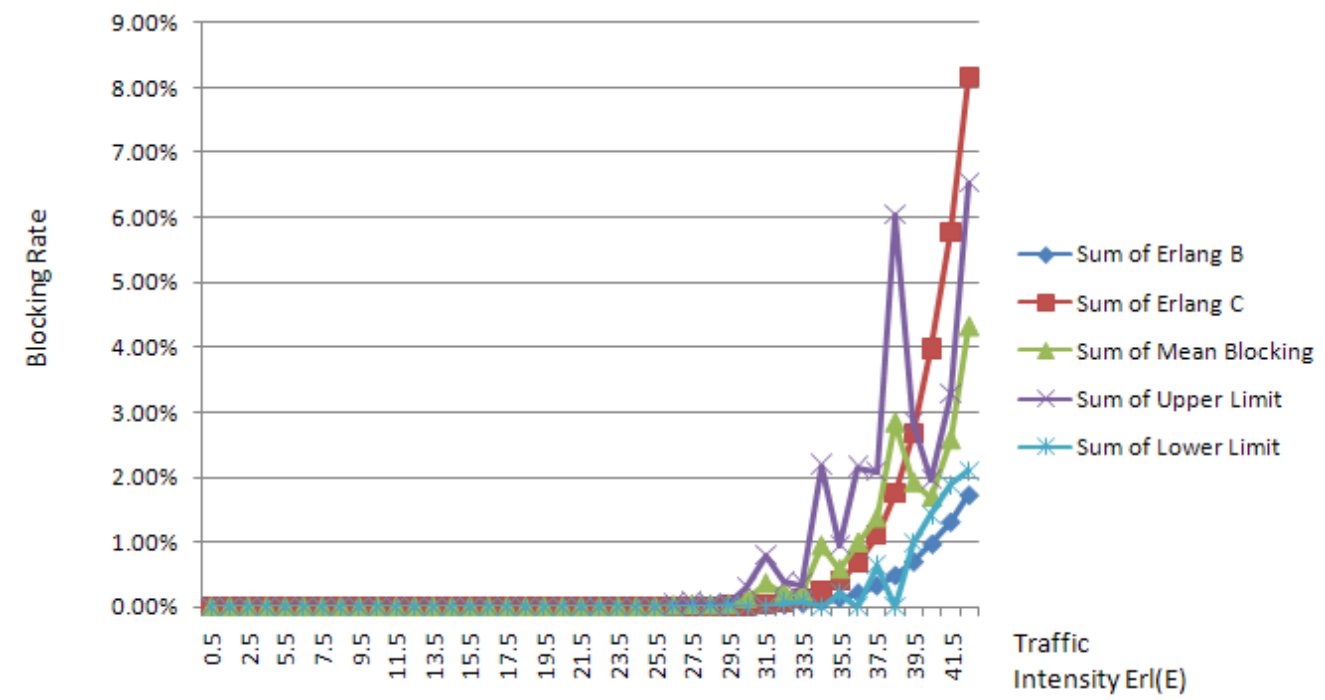

Figure 10. Confidence interval for all cells with $53 \mathrm{TCH}$.

The distribution of samples with respect to the traffic bin each at an interval of 1 Erlang is shown in the form of a histogram in Figure 11. The measurement window is based on a 24-hour range sampled at interval of 60 minutes as a general rule. It can be seen that a normal bell shaped distribution is obtained.

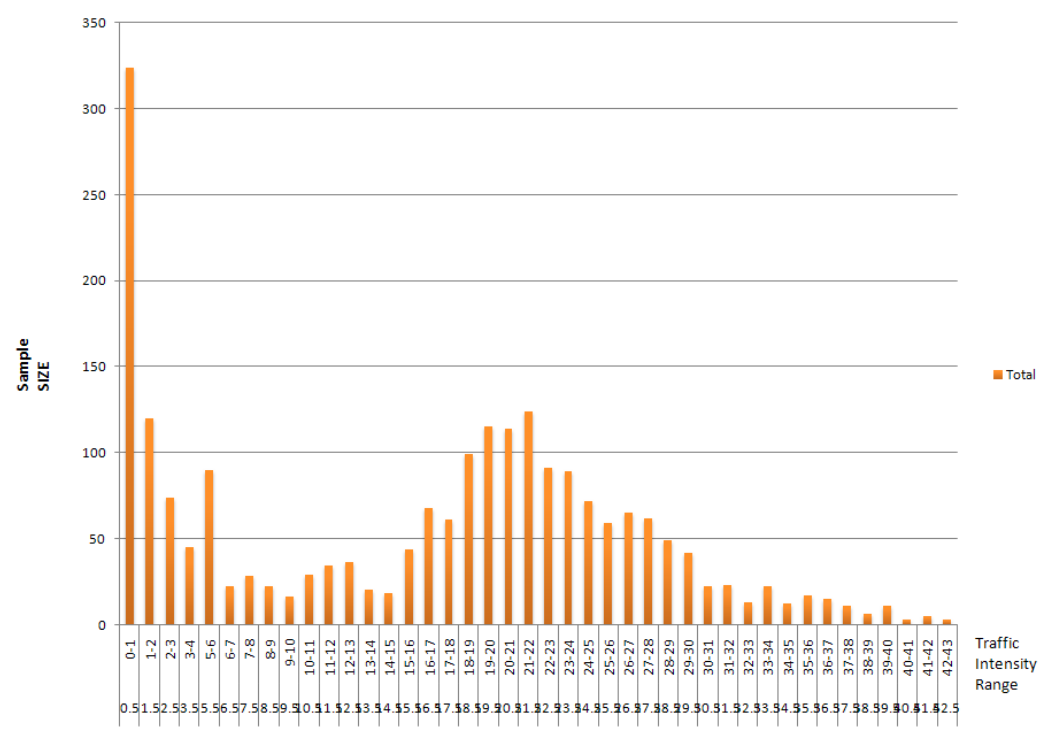

Figure 11. Sample distribution for all cells with $53 \mathrm{TCH}$.

Based on the above, it can be said that the Erlang $\mathrm{C}$ model is appropriate for the studied network. The samples are evenly distributed on the network, and as 24-hour sampling is used, there are several samples with low traffic intensity. We also note that in some cases, Erlang C did not provide the best fit because of GSM features change the configuration of the cell dynamically and therefore it may happen that less traffic channels are available instantaneously thus causing more blocking. In Figure 12, we show the graph of traffic intensity against time for $53 \mathrm{TCH}$ cell in a rural commercial area from Monday to Sunday. 
International Journal of Wireless \& Mobile Networks (IJWMN) Vol. 3, No. 6, December 2011

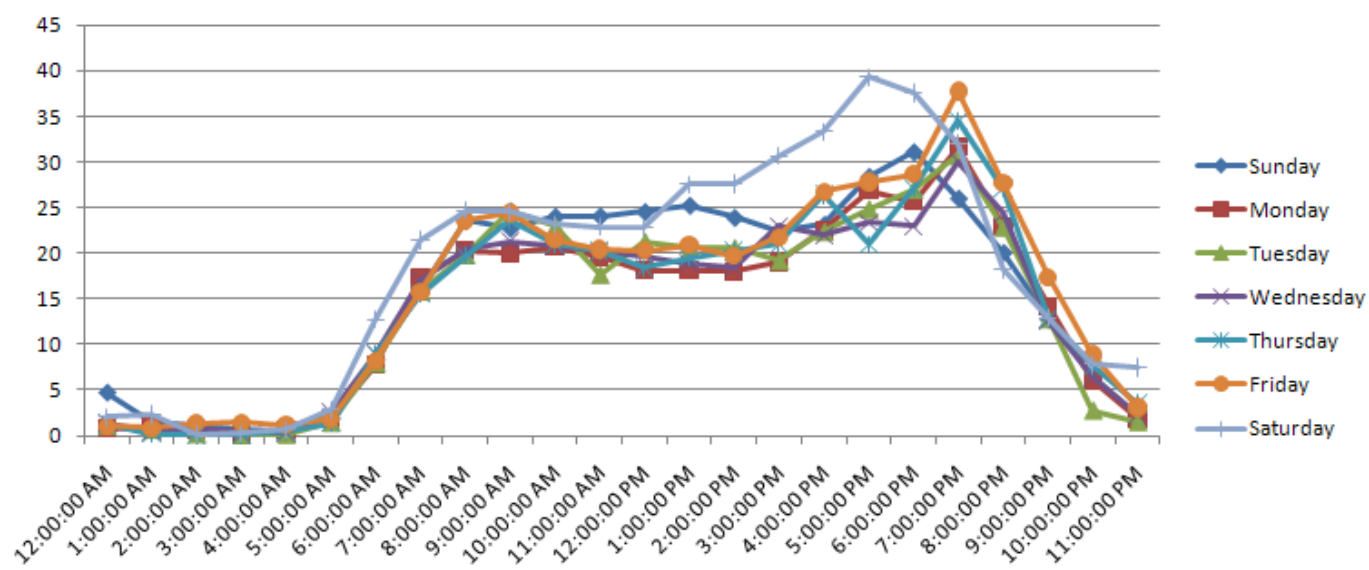

Figure 12. Traffic intensity against time for $53 \mathrm{TCH}$ cell in a rural commercial area from Monday to Sunday.

\subsection{Half Rate Traffic}

In Figures 13 to 16, the shaded boundaries indicate where half rate traffic is considered on the traffic plots. We observe that mixed traffic is triggered from solely normal full rate traffic to half rate traffic.

Figures 14, 15 and 16 indicate that the measured samples fit within the boundary for most cells. However for Figure 13 which considers cells with lower amount of channels, it is seen that some samples are still outside the boundary which is due to the limited amount of channels and GSM feature of dynamic channel allocation.

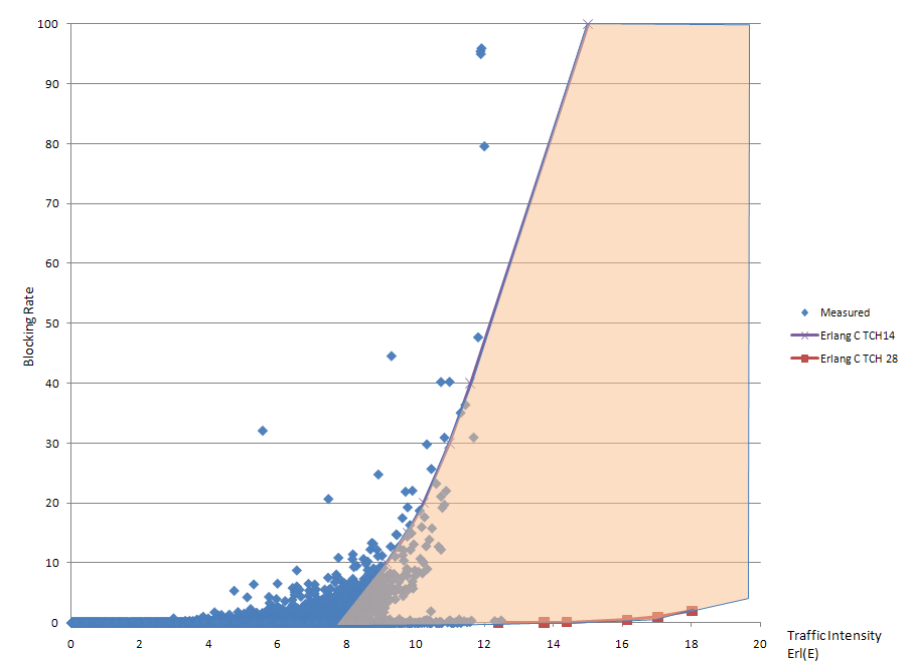

Figure 13. Graph of blocking rate against traffic intensity for $14 \mathrm{TCH}$ with performance information and the acceptable range. 
International Journal of Wireless \& Mobile Networks (IJWMN) Vol. 3, No. 6, December 2011

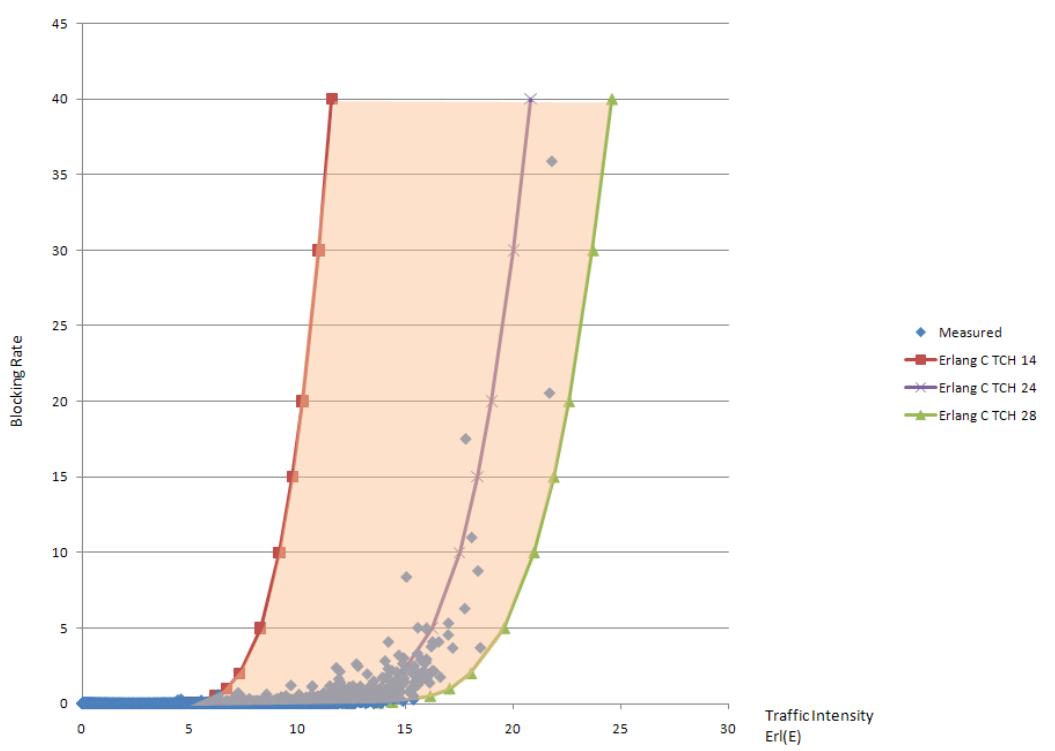

Figure 14. Graph of blocking rate against traffic intensity for $24 \mathrm{TCH}$ with performance information and the acceptable range.

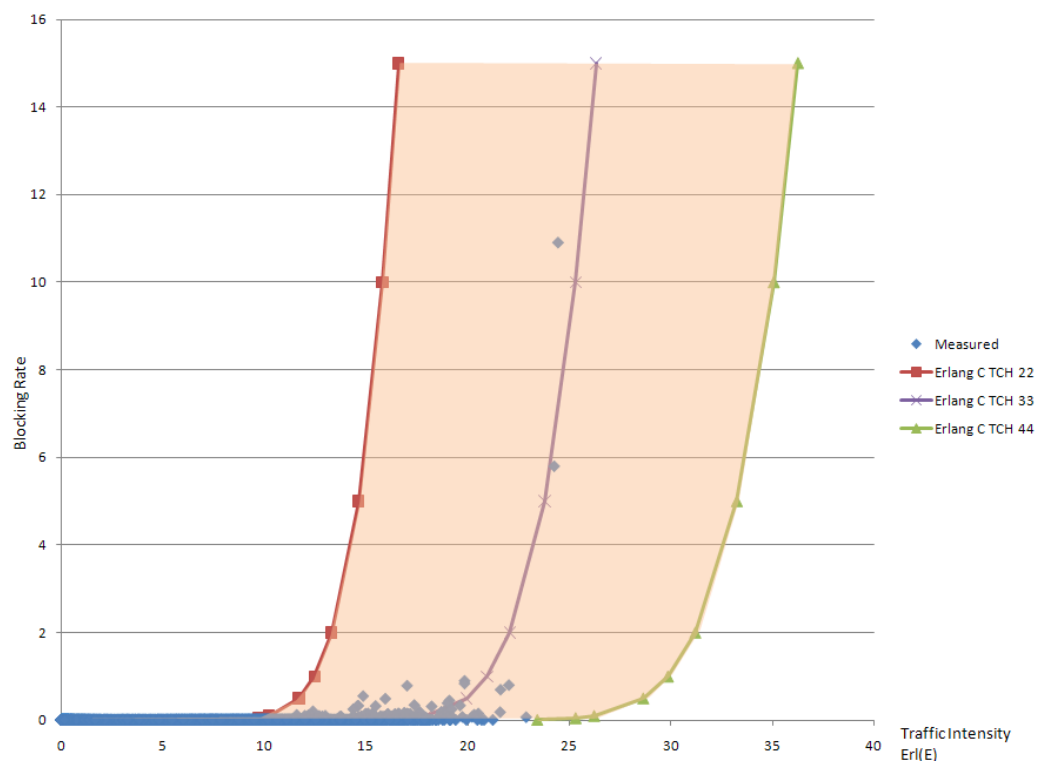

Figure 15. Graph of blocking rate against traffic intensity for $33 \mathrm{TCH}$ with performance information and the acceptable range. 


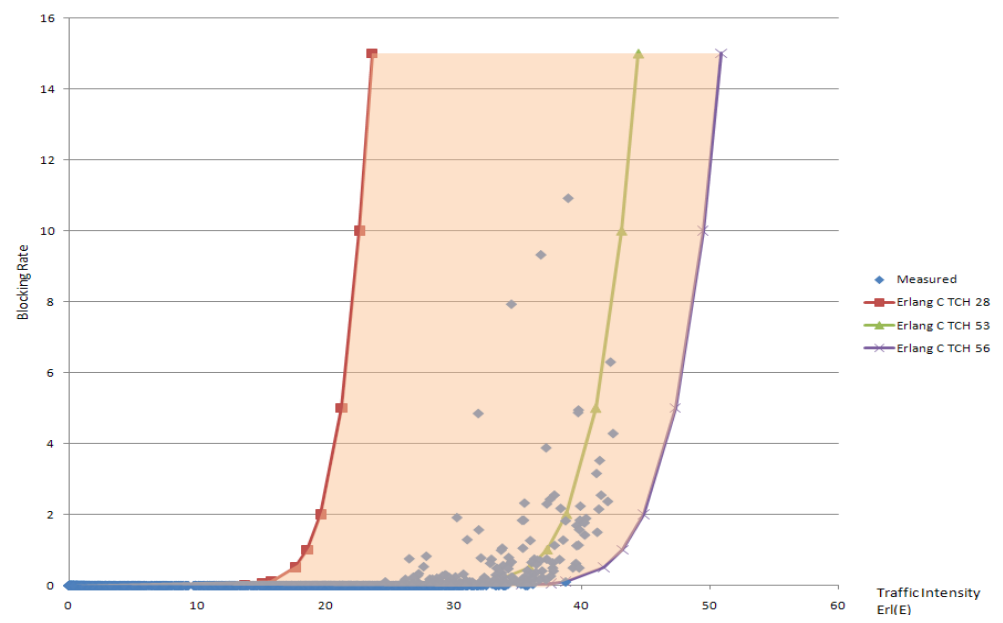

Figure 16. Graph of blocking rate against traffic intensity for $53 \mathrm{TCH}$ with performance information and the acceptable range.

\section{CONCLuSion}

We have observed that cells with more than 14 channels have a behaviour which show a good fit to Erlang C theoretical values. We also note that activation of GSM enhanced features such as GSM Half Rate speech codec does help the network by reducing blocking probabilities.

From the analysis, it can be concluded that the studied network is properly sized and the probability of high blocking is quite low and occurs only during the busiest hour, which is normal. The network operates within industry standards for Grade of Service which should lead to user satisfaction with respect to network accessibility.

We note that new GSM features, which are traffic control measures, do provide a lot of benefits to cellular networks in the sense that they help to reduce blocking. When dynamic channel allocation is enabled, cell configuration is dynamic with respect to time and a dimensioning exercise becomes more difficult due to the number of channels being variable and subject to traffic load.

Smith et al. [15] and Tunnicliffe et al. [16] have mentioned that the real blocking faced on network with cells with low number of channel is less than the blocking predicted by the traffic model which they have considered. This is in line with the results which we have obtained. However, blocking depends on the number of subscribers and the arrival rate. Based on the observations obtained from our experimental work, we have found that both Erlang $\mathrm{C}$ and Poisson converge towards the same values as the number of resources increases for our model network. Furthermore, using Erlang $\mathrm{C}$ is proposed as it will give higher blocking values which would lead the operator to have extra capacity margins when relevant cell expansions are made.

\section{REFERENCES}

[1] Baky, S. and Ackroyd, M. (1981) "Teletraffic Analysis for Single-Cell Mobile Radio Telephone Systems" IEEE Transactions on Communications, vol. 29, no.3, pp298-304

[2] Baky, S. and Ackroyd, M. (1982) "Teletraffic Analysis for Multicell Mobile Radio Telephone Systems" IEEE Transactions on Communications, vol. 30, no. 8, pp1905-1909

[3] Everit, D. E. (1994) "Traffic Engineering of the Radio Interface for Cellular Mobile Networks" Proceedings of the IEEE, vol. 82, No. 9, pp1371-1382

[4] Freeman, R. (2004) Telecommunications System Engineering, John Wiley \& Sons 
International Journal of Wireless \& Mobile Networks (IJWMN) Vol. 3, No. 6, December 2011

[5] Guerin, R. A. (1987) "Channel Occupancy Time Distribution in a Cellular Radio System” IEEE Transactions on Vehicular Technology, vol. 36, no. 3, pp89-99

[6] Hillebrand, F. (2001) GSM and UMTS: The Creation of Global Mobile Communication, John Wiley \& Sons

[7] Jabbari, B. (1996) "Teletraffic Aspects of Evolving and Next Generation Wireless Communication Networks', IEEE Personal Communications, vol.3, no. 6, pp4-9

[8] Jedrzycki, C. and V. C. M. Leung (1996) "Probability Distribution of Channel Holding Time in Cellular Telephony Systems", Proceedings of the IEEE Vehicular Technology Conference, vol. $1,247-251$

[9] Karray, M. K. (2010) "Evaluation of the blocking probability and the throughput in the uplink of wireless cellular networks", Proceedings of the International Conference on Communications and Networking, pp1-8

[10] Kolaczyk, E. D. (2010) Statistical Analysis of Network Data: Methods and Models, Springer

[11] Nasser, N. (2006) "An acceptable trade-off between new call blocking and handoff call dropping probabilities in multimedia cellular networks", Proceedings of the 4th Communication Networks and Services Research Conference, pp69-75

[12] Oancea, C. D. (2011) "GSM infrastructure used for data transmission", Proceedings of the $7^{\text {th }}$ International Symposium on Advanced Topics in Electrical Engineering, pp1-4

[13] Perkov, L., Klisura, A. and Pavkovic, N. (2011) "Recent Advances in GSM Insecurities" Proceedings of the MIPRO $34^{\text {th }}$ International Convention, pp1502-1506

[14] Rappaport, S. S. and Lon-Rong Hu (1994) "Microcellular Communication Systems with Hierarchical Macrocell Overlays: Traffic Performance Models and Analysis", Proceedings of the IEEE, vol. 82, no. 9, pp1383-1397

[15] Smith, P. J., Sathyendran, A. and Murch, A. R., (1999) "Analysis of Traffic Distribution in Cellular Networks", Houston, TX, USA: 49 IEEE Vehicular Technology Conference, pp20752079

[16] Tunnicliffe, G. W., Murch, A. R., Sathyendran, A. and Smith, P. J., (1998) "Analysis of Traffic Distribution in Cellular Networks", $48^{\text {th }}$ IEEE Vehicular Technology Conference IEEE, pp19841988

[17] Information and Communication Technologies Authority of Mauritius ICTA., (2011) "Mobile Telephony Services and mobile Rate", http://www.icta.mu/market/mobile_telephony.htm, Last Accessed 2011-12-17

[18] Lange, P. (2010) "Mauritius - Telecoms, Mobile, Broadband and Forecasts", http://www.budde.com.au/Research/Mauritius-Telecoms-Mobile-Broadband-and-Forecasts.html Last Accessed 2011-12-17

\section{Acronyms}

BCCH Broadcasting Control Channel (Control Info)

$\begin{array}{ll}\text { BSS } & \text { Base station subsystem } \\ \text { GSM } & \text { Groupe Spécial Mobile } \\ \text { KPI } & \text { Key Performance Indicator } \\ \text { TCH } & \text { Traffic Channels } \\ \text { TRX } & \text { Transmitter/Receiver (Transceiver) } \\ \text { PDCH } & \text { Packet Data Channel (Data Traffic) } \\ \text { SDCCH } & \text { Slow Dedicated Control Channel (Signalling) }\end{array}$


International Journal of Wireless \& Mobile Networks (IJWMN) Vol. 3, No. 6, December 2011

\section{Authors}

Olivier Mitch Maguitte received his BSc (Hons) in Computer Science with Network Security (First Class) and MSc Computer Networking with distinction in 2007 and 2010 respectively.

Mohammad Sameer Sunhaloo completed his BSc (Hons) Mathematics with First Class Honours in 1999. He completed successfully his $\mathrm{PhD}$ in Computational Mathematics in 2006. He is currently a senior lecturer at the University of Technology, Mauritius. His fields of study are scientific computing and numerical linear algebra.

Ben Oodit completed a BSc (Hons) in Electrical and Electronic Engineering with First Class Honours in 1987 from University of Manchester Institute of Science and Technology (UMIST). He completed successfully his PhD in Adaptive Digital Communications in 1990. He has since been very active in the ICT environment. He is a Chartered Engineer (UK) and a member of the IET and of the IEEE.

Vinaye Armoogum received his BSc (Eng) in Computer Engineering and MSc (Eng) in System Engineering in 1995 and 1997 respectively. He completed successfully his $\mathrm{PhD}$ in Telecommunications in 2009. He is currently a senior lecturer at the University of Technology, Mauritius. His fields of study are telecommunications and related areas, computer science and engineering. 